\title{
Coupled semiconductor nanosystems for enhanced photocatalytic applications
}

\author{
Sudhir S. Arbuj* and Sunit B. Rane \\ Renewable Energy and Sensor Materials Division, \\ Centre for Materials for Electronics Technology (C-MET), Off Pashan Road, \\ Panchwati, Pune-411008, Maharashtra, India \\ Email: sudhir1305@gmail.com, sudhir@cmet.gov.in
}

Heterogeneous photocatalysis using Nanostructured semiconductors have been actively studied for various environmental and energy related applications. In 1972, Fujishima and Honda for the first time reported the generation of $\mathrm{H}_{2}$ from water using $\mathrm{TiO}_{2}$ as a photo-anode in presence of ultraviolet light [1]. Since then enormous amount of efforts were taken to generate the $\mathrm{H}_{2}$ via photocatalytic water splitting. The photocatalytic activity of the catalyst mainly depends upon the band gap and band positions of the materials. Till today various semiconductor oxides as well sulfides have been exploited viz. $\mathrm{TiO}_{2}, \mathrm{ZnO}, \mathrm{SnO}_{2}, \mathrm{WO}_{3}$, $\mathrm{Fe}_{2} \mathrm{O}_{3}, \mathrm{CdS}, \mathrm{ZnS}, \mathrm{SnS}_{2}$ and so on, as photocatalyst for energy as well as environment related applications [2]. In order to enhance the activity of catalyst various modifications have been tried, like doping of cations and anions in the existing catalyst, loading of noble metals to minimize the generated electron hole recombination's etc. Furthermore, the change in synthesis methods showed change in the photocatalytic activity as function of surface area and crystallinity.

Recently, Coupled semiconductor systems of oxide/oxide as well as sulphide/oxide type also reported to have enhanced photoactivity [3]. This enhanced photoactivity is due to two important reasons. First, in the coupled semiconductor systems contains different energy levels, wide band-gap semiconductors can utilize visible light by coupling narrow band-gap semiconductors. Second, charge injection from one semiconductor into another can lead to efficient and longer charge separation by reducing the electron-hole pair recombination's.

Herein, we have prepared the $\mathrm{CdS} / \mathrm{ZnO}$ nanostructured catalytic system with variation of CdS mol\% from 0.1 to 5 and studied their photocatalytic activity towards water splitting. Apart from this we also investigated the photocatalytic activity of $\mathrm{Nb}_{2} \mathrm{O}_{5} / \mathrm{TiO}_{2}$ and $\mathrm{Ta}_{2} \mathrm{O}_{5} / \mathrm{TiO}_{2}$ towards methylene blue (MB) degradation. The synthesized materials were thoroughly analyzed with various spectroscopic techniques. For $\mathrm{CdS} / \mathrm{ZnO}$ nanosystem, we have prepared 1D $\mathrm{ZnO}$ using solvothermal reaction technique and then loading of $\mathrm{CdS}$ on $\mathrm{ZnO}$ rods were done using microwave reaction technique. The photocatalytic activity of prepared coupled $\mathrm{CdS} / \mathrm{ZnO}$ shows increase in hydrogen generation as compared to individual ones. The CdS loading enhances the rate of $\mathrm{H}_{2}$ generation and is the highest for $5 \mathrm{~mol} \% \mathrm{CdS} / \mathrm{ZnO}$ composition.

The detail photocatalytic water splitting mechanism is shown in Figure 1.

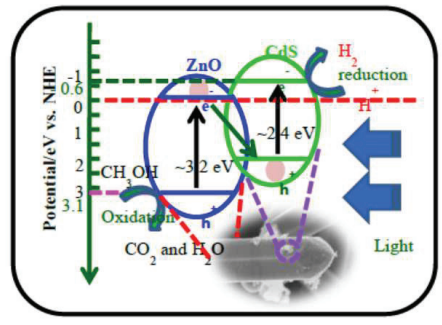

Figure 1: Photocatalytic $\mathrm{H}_{2} \mathrm{O}$ splitting mechanism

The graph of amount of $\mathrm{H}_{2}$ produced Vs irradiation time for different compositions of $1 \mathrm{D} \mathrm{CdS} / \mathrm{ZnO}$ coupled catalyst are shown in Figure 2.

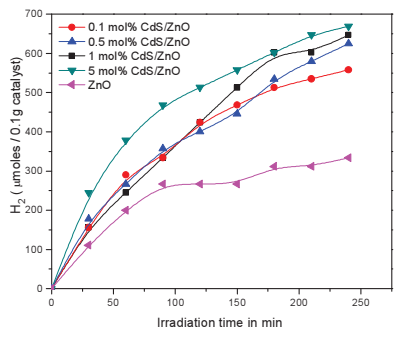

Figure 2 Photocatalytic $\mathrm{H}_{2}$ generation via $\mathrm{H}_{2} \mathrm{O}$ splitting

The pure $\mathrm{ZnO}$ shows $300 \mu$ moles of $\mathrm{H}_{2}$ after $4 \mathrm{~h}$ of irradiation. As the amount of $\mathrm{CdS}$ loading increases the $\mathrm{H}_{2}$ evolution also increases.

\section{References}

1. A. Fujishima and K. Honda, Nature, 238 (1972) 37.

2. M. R. Hoffmann, S. T. Martin, W. Choi, D. W. Bahnemann, Chem. Rev., 95 (1995) 69.

3. S. S. Arbuj, U. P. Mulik and D. P. Amalnerkar, Nanosci. Nanotechnol. Lett., 5 (2013) 968. 